\title{
Introduction: Exotic pests
}

C alifornia's prominent position on the Pacific Rim, favorable climate, popularity among tourists and abundant agriculture make it particularly vulnerable to exotic pests. A new exotic pest threatens the state's agricultural, natural and urban environments every 60 days.

Agricultural pests, such as the tiny but destructive silverleaf whitefly, are expensive neighbors; the whitefly has cost California agriculture $\$ 1$ billion since 1991. Urban pests can be equally devastating. Now believed to be established in San Diego County, the Formosan termite could cost $1 \%$ of the total value of wooden structures throughout the state.

With its mandate to prevent the entry and establishment of harmful exotic pests, CDFA's monitoring and eradication efforts are also significant. In the past 4 years, for the Mediterranean fruit fly alone, these efforts have cost an estimated \$131 million, shared equally by state and federal government.

In the research articles that follow, UC scientists present the current scientific thought on a number of major exotic pests. We begin with three brief news articles, including a look at the UC Center for Exotic Pest Research (CEPR).

By focusing exclusively on exotic pests, the CEPR fills a specialized niche within the university. CEPR is distinct from UC's Center for Pest Management Research and Extension, which serves as a statewide clearinghouse of information and coordinator of research. It is also distinct from the Statewide Integrated Pest Management Project, which develops IPM strategies for established agricultural pests. $-E d$.

\section{Center for Exotic Pest Research tackles controversy}

$\mathrm{D}_{\mathrm{s}}$ iscoveries of Mediterranean fruit flies in Southern California in 1993 and 1994 led to the threat of a Japanese trade embargo, public outcry over malathion spraying, and heated scientific debate over the establishment of the pest.

This crucible of public and scientific controversy would lead to the formation of the UC Center for Exotic Pest Research (CEPR) in September 1994. In November 1994, the center brought together more than 40 internationally renowned scientists to discuss medfly research. They emerged with a consensus report embraced by the U.S. Department of Agriculture (USDA), the California Department of Food and Agriculture (CDFA), and UC scientists.

CEPR continues to play an important research and extension role in dealing with exotic fruit flies. In 1998, CEPR will assist in evaluating the medfly sterile insect technique and in improving the release program. Research conducted with USDA in Hawaii and at the Los Alamitos sterile release facility will focus on rearing methods, quality control, and longevity and fate of sterile flies released in California. Scientific evaluation of the program is particularly crucial because of recent medfly finds in Walnut Park, which have sparked debate.
Another contentious issue tackled by CEPR, based at UC Riverside, is the impact of newly liberalized trade policies on the introduction of exotic pests. CEPR was asked to review a proposed rule by the USDA's Animal and Plant Health Inspection Service (APHIS) allowing importation of fresh Mexican Hass avocados into the United States. A risk assessment published by CEPR found the proposed rule and the work plan submitted by Mexico provided ineffective safeguards for the protection of California agriculture from a number of exotic pests. CEPR's intercampus team of UC scientists further concluded that APHIS had been forced into a conflict of interest when they were asked to facilitate international (import) trade while attempting to maintain its historic mandate of preventing the introduction and establishment of exotic pests.

In February, the Subcommittee on Trade of the House Ways and Means Committee held hearings to examine U.S. efforts to reduce trade barriers in agriculture. CEPR director Joseph Morse testified, in part, "The movement of nonindigenous pest species throughout the world will be accelerated by new free trade agreements such as NAFTA and GATT ... California, with the largest agricultural industry, the greatest crop
"The movement of ... pest species throughout the world will be accelerated by new free trade agreements ..." 